\title{
El estilo cerámico Carmen y su presencia en el valle medio de Chincha, costa sur del Perú
}

Le style céramique Carmen et sa présence dans la moyenne vallée de Chincha, côte sud du Pérou

The Carmen Ceramic Style and Its presence in the Chincha Middle valley, Peruvian Southern Coast

Kelita Pérez, Abel Fernández, Henry Tantaleán y Charles Stanish

\section{OpenEdition}

Journals

Edición electrónica

URL: https://journals.openedition.org/bifea/7555

DOI: $10.4000 /$ bifea.7555

ISSN: 2076-5827

\section{Editor}

Institut Français d'Études Andines

\section{Edición impresa}

Fecha de publicación: 1 agosto 2015

Paginación: 181-204

ISSN: 0303-7495

\section{Referencia electrónica}

Kelita Pérez, Abel Fernández, Henry Tantaleán y Charles Stanish, «El estilo cerámico Carmen y su presencia en el valle medio de Chincha, costa sur del Perú», Bulletin de l'Institut français d'études andines [En línea], 44 (2) | 2015, Publicado el 08 agosto 2015, consultado el 21 septiembre 2021. URL: http://journals.openedition.org/bifea/7555 ; DOl: https://doi.org/10.4000/bifea.7555

\section{(c) $(1) \odot$}

Les contenus du Bulletin de l'Institut français d'études andines sont mis à disposition selon les termes de la licence Creative Commons Attribution - Pas d'Utilisation Commerciale - Pas de Modification 4.0 International. 


\title{
El estilo cerámico Carmen y su presencia en el valle medio de Chincha, costa sur del Perú
}

\author{
Kelita Pérez* \\ Abel Fernández** \\ Henry Tantaleán $n^{* * *}$ \\ Charles Stanish ${ }^{* * * *}$
}

\begin{abstract}
Resumen
En este artículo se describe y discute la cerámica asociada a lo que se conoce en la literatura arqueológica como la «Fase o Estilo Carmen» (circa 200-400 d. C.) recuperada en nuestras recientes investigaciones en los sitios de Cerro del Gentil y Pampa del Gentil, ubicados en el valle medio de Chincha, en la costa sur del Perú. La presentación hecha aquí del análisis de la cerámica recolectada y su contexto de recuperación nos acercan a la comprensión de la ocupación humana que habrían tenido estos sitios que, por lo general, se han relacionado con la sociedad Nasca.
\end{abstract}

Palabras Clave: costa sur del Perú, valle de Chincha, Periodo de los Desarrollos Regionales Tempranos, Estilo o Fase Carmen

\section{Le style céramique Carmen et sa présence dans la moyenne vallée de Chincha, côte sud du Pérou}

\section{Résumé}

Cet article décrit et analyse la céramique associée à ce que I'on connaît dans la literature archéologique comme Phase ou Style Carmen (circa 200-400 a. J.C.) trouvées récemment sur les sites Cerro del Gentil et Pampa del Gentil situés dans la moyenne vallée de Chincha, sur la côte sud du Pérou. La

* Universidad Nacional de Trujillo. E-mail: kelitacubas@yahoo.es

** Universidad Nacional Mayor de San Marcos. E-mail: narmer21@hotmail.com

*** Instituto Francés de Estudios Andinos, Lima. E-mail: henrytantalean@yahoo.es

${ }^{* * * *}$ Cotsen Institute of Archaeology, University of California at Los Angeles. E-mail: stanish@ucla.edu 
présentation de l'analyse de la céramique collectée et des caractéristiques de la récupération permet de mieux comprendre l'occupation humaine de ces sites généralement associés à la société Nasca.

Mots-clés : côte sud du Pérou, vallée de Chincha, Période des Développements Régionaux Anciens, style ou phase Carmen

\title{
The Carmen Ceramic Style and Its presence in the Chincha Middle valley, Peruvian Southern Coast
}

\begin{abstract}
This article describes and discusses the ceramics known in the archaeological literature as "Carmen Phase or Style" (circa $200-400$ AD) that were recovered in our recent research at the sites of Cerro del Gentil y Pampa del Gentil, located in the mid Chincha valley, at the south coast of Peru. The analysis of the pottery and its archaeological contexts provide us with a better understanding of human occupation of these sites mainly related with Nasca Society.
\end{abstract}

Keywords: Peruvian Southern Coast, Chincha Valley, Early Regional Developments Period, Carmen Style or Phase, domestic areas

\section{INTRODUCCIÓN}

La costa sur peruana es un área de los Andes Centrales que, en la época prehispánica, fue el hogar de una serie de grupos sociales que desarrollaron una importante producción material que los ha hecho conocidos a nivel mundial. En esta área se desarrollaron originalmente las sociedades Paracas, Nasca y Chincha, sociedades que tuvieron un gran impacto en otras sociedades andinas en el pasado y en el presente han cautivado a legiones de estudiosos desde el siglo XIX (Middendorf, 1973 [1894); Uhle, 1924; Tello \& Mejía Xesspe, 2005 [1959]; Lumbreras, 2001; Silverman, 2002; Proulx, 2008, etc.). Sin embargo, la existencia de tales sociedades en dicha área también ha oscurecido la comprensión de otros grupos locales cuyo desarrollo histórico queda mal conocido hasta ahora. Una de ellas es la que se vinculó con el estilo conocido en la arqueología peruana como Carmen y que fue contemporánea con la sociedad Nasca cuyo centro principal fue el sitio de Cahuachi, ubicado en el valle del río Grande (Silverman \& Proulx, 2002; Proulx 2008).

Para poder entender, para la época prehispánica, el largo proceso que se da en un área, es necesario además reconocer las grandes sociedades que ocuparon la zona; también identificar y explicar a aquellas que tuvieron importancia local para, de este modo, obtener un mejor panorama del proceso histórico. Con tal motivo, nuestras recientes investigaciones arqueológicas se han concentrado en el valle medio de Chincha y, específicamente, en los sitios arqueológicos denominados Cerro del Gentil y Pampa del Gentil (fig. 1). De acuerdo con 


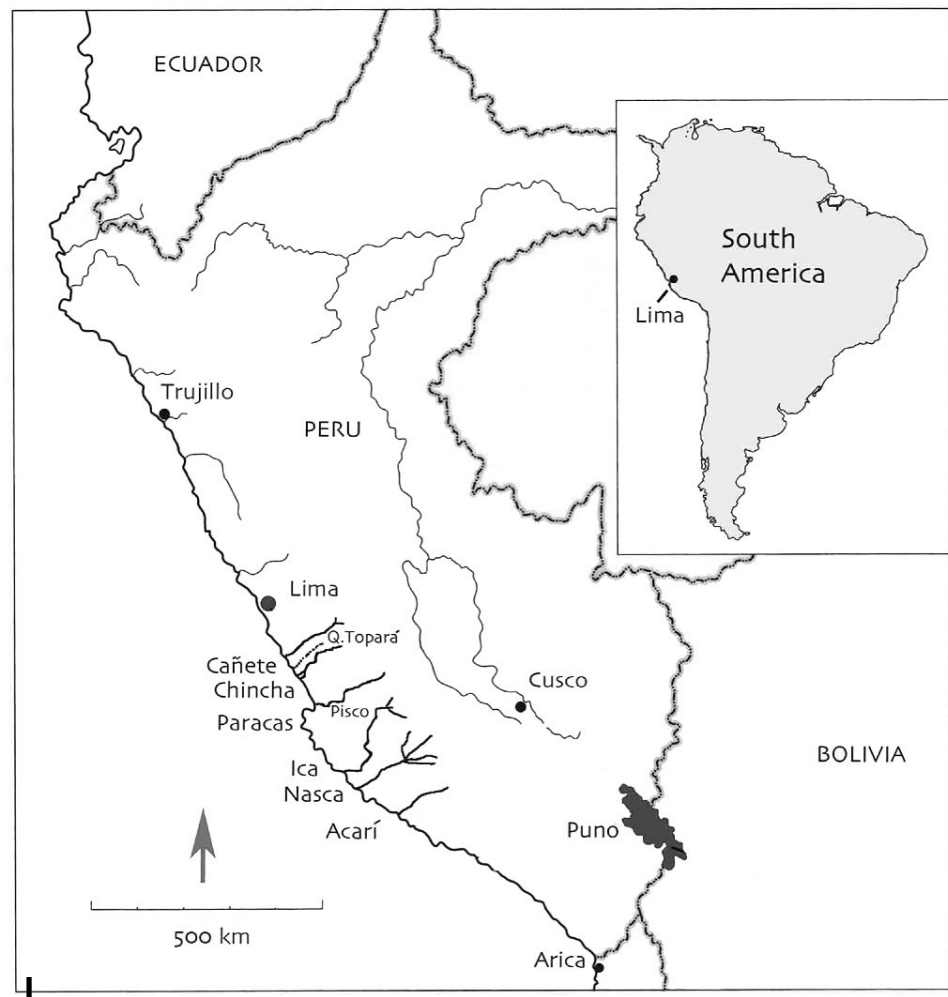

Figura 1 - El valle de Chincha en el contexto del Perú

(C) Charles Stanish

investigaciones previas y las nuestras, ambos sitios poseen ocupaciones humanas asociadas al estilo o fase ${ }^{1}$ Carmen (200-400 d. C.) relacionado temporalmente con el periodo conocido en la arqueología peruana como el «Periodo de los Desarrollos Regionales Tempranos»(200 a. C.-600 d. C.).

En este artículo nos enfocamos en la descripción y análisis de la cerámica del estilo Carmen recuperada en ambos sitios, lo cual nos permite 1) acrecentar el corpus de

1 Como veremos más adelante, en autores como Wallace y otros posteriores, se encuentra muy extendido el uso del término «fase Carmen». Obviamente, el objetivo de Wallace era establecer una secuencia cerámica para los valles de Chincha y Pisco, especialmente y, para ello, acomodó sus «fases» en una secuencia ordenada temporalmente que, además, se correlacionara con las secuencias existentes como la de Ica (Menzel et al., 1964). En algunos casos, las fases propuestas por Wallace parecen funcionar. Sin embargo, como muchos otros autores han notado (Peters, 1997; Castro-Martínez et al., 2009), muchas de estas supuestas fases conviven en el tiempo, por lo cual pierden esa capacidad cronológica secuencial. Por ello, aquí preferimos utilizar la categoría «estilo», pues nos aproxima más a la producción social de un tipo de cerámica con características propias, independientemente de una ubicación temporal secuencial. Sin embargo, también como veremos, el concepto de fase es algo muy arraigado en la literatura de la zona y de la cual aún no podemos prescindir e, incluso, es necesario para seguir el razonamiento de los autores. 
este estilo, 2) establecer cuáles fueron las funciones principales de esta cerámica en base a su producción, uso y contexto en el que fueron encontrados, 3) revisar su vinculación con la cerámica de estilo Nasca y 4) avanzar en el entendimiento del tipo de relación entre los usuarios de la cerámica Carmen y Nasca.

\section{EL SITIO ARQUEOLÓGICO DE CERRO DEL GENTIL (PV. 57-59)}

Tanto Cerro del Gentil como Pampa del Gentil se encuentran ubicados políticamente en el distrito de El Carmen, provincia de Chincha en el departamento de Ica, en la costa sur del Perú (fig. 2). Cerro del Gentil se encuentra en la margen sur del valle de Chincha, específicamente en el ramal denominado río Matagente, cuando el valle comienza a estrecharse camino a la sierra (fig. 3). El sitio se construyó sobre una saliente de la terraza aluvial, en un área al borde de la pampa que se eleva encima del fondo del valle cultivado, a unos 200 m.s.n.m. y que está delimitada por el norte por la quebrada Puerta Blanca.

Cerro del Gentil fue descrito científicamente por primera vez por Dwight Wallace y se refirió a este como PV.57-59 (Lanning, 1960: 417; Wallace, 1971). Durante la década de los años 1980 el «Proyecto Histórico-Arqueológico Chincha-Pisco» dirigido por Luis Guillermo Lumbreras, quien acompañó en la década de 1950 a

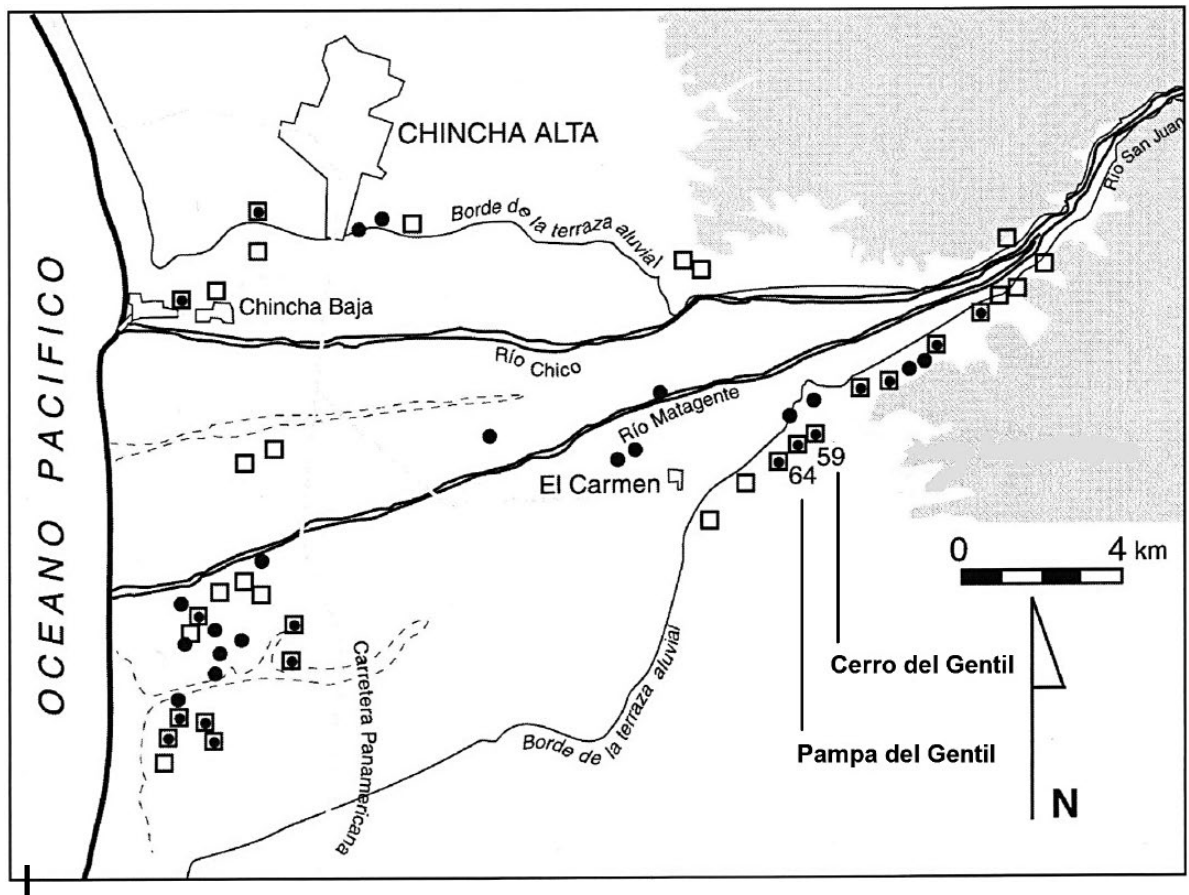

Figura 2 - Mapa del valle de Chincha con la ubicación de Cerro del Gentil y Pampa del Gentil (c) Modificado de Leonid Velarde, 2006: fig. 2 


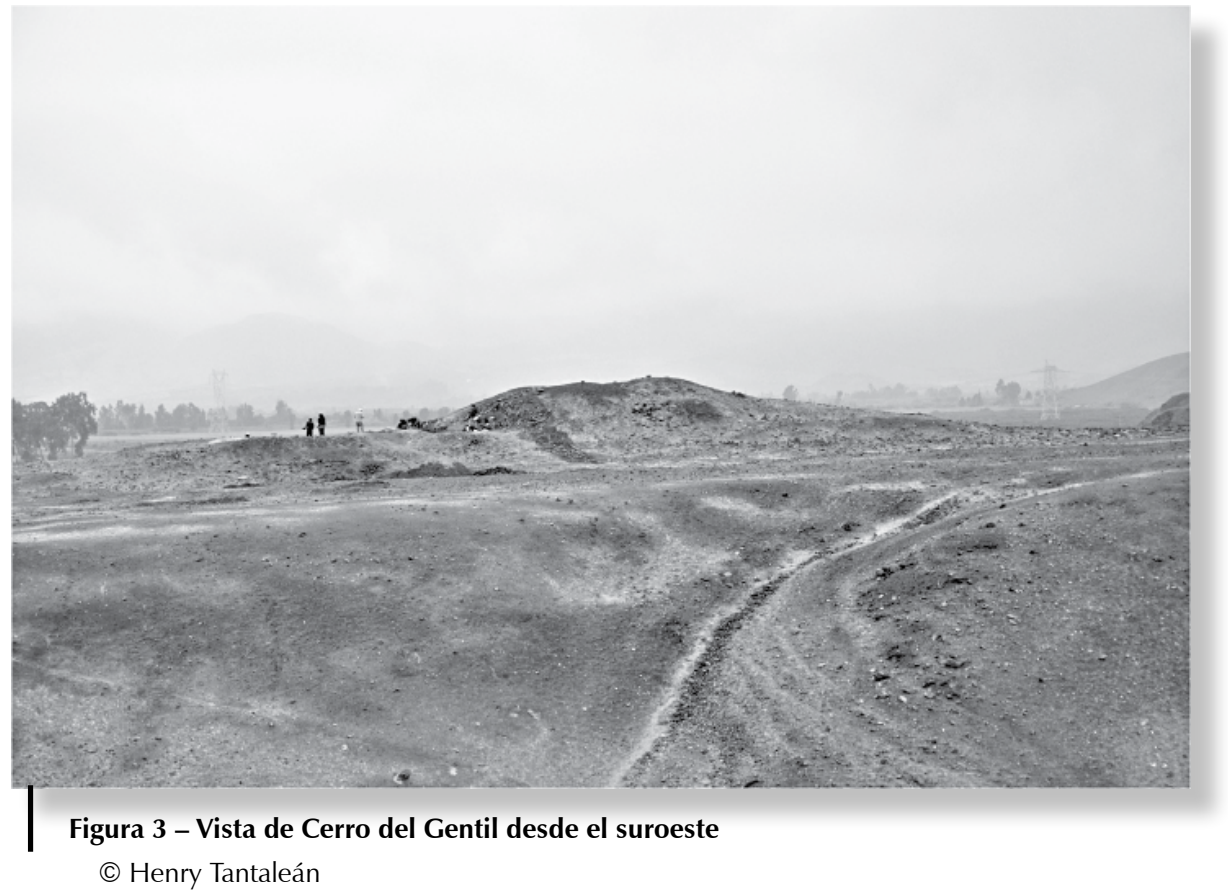

Wallace en sus prospecciones, realizó trabajos en esta zona y excavó en el sitio de El Mono o Chococota, ubicado al suroeste de Pampa del Gentil. De la síntesis que escribió Lumbreras (2008: 34-39) se reconoce que tanto El Mono como Cerro del Gentil comparten un estilo cerámico denominado por Wallace como Pinta ${ }^{2}$ y definido desde sus recolecciones de superficie en El Mono (PV.57-63) (Lanning, 1960: 417).

Cerro del Gentil es un sitio compuesto principalmente por dos montículos artificiales, uno menor y otro mayor. El montículo mayor está conformado por diferentes plataformas, con una planta rectangular de $70 \times 30 \mathrm{~m}$. Al centro de la plataforma principal, se levanta una construcción que tiene $25 \times 25 \mathrm{~m}$ de base y alcanza aproximadamente $5 \mathrm{~m}$ de altura (Canziani, 1992: 105). Este autor considera que este sitio es uno de los principales sitios Paracas en esta parte del valle ya que contiene cerámica y arquitectura propia del periodo (fig. 4).

2 De hecho, Wallace definió un estilo denominado Pinta. Este estilo se caracterizaría por vasijas con decoraciones de círculos realizados tanto con la técnica en negativo como con pintura poscocción. Sin embargo, este estilo no sería más que un subestilo del estilo Paracas Cavernas definido por Julio C. Tello (Tello \& Mejía Xesspe, 2005 [1959]). 


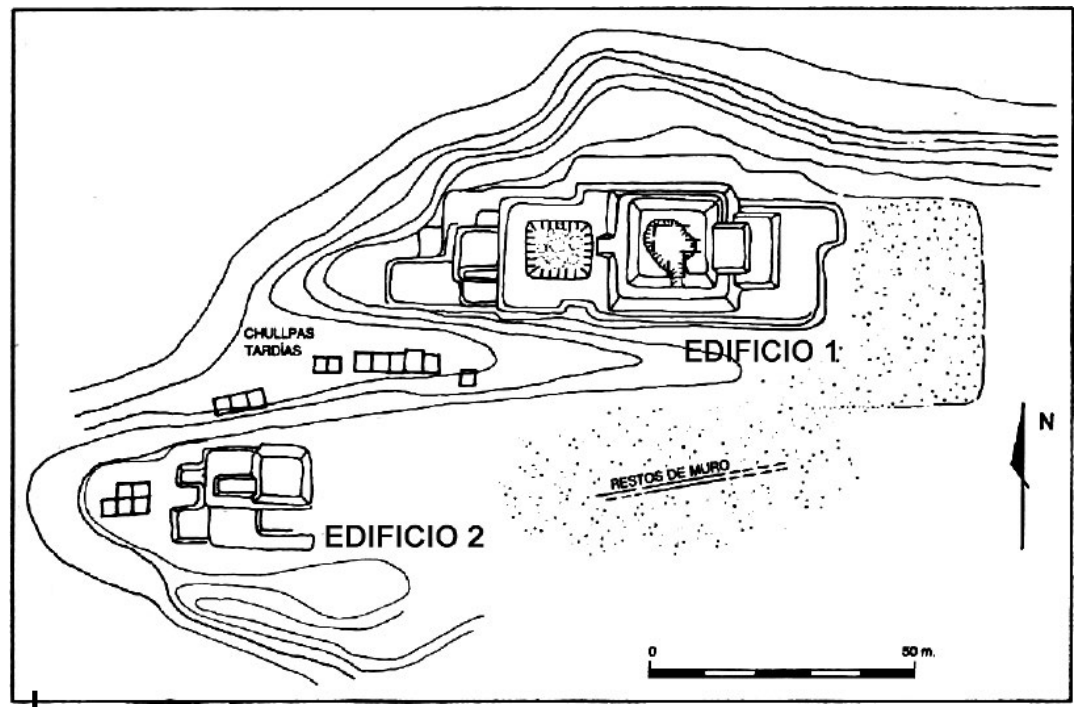

Figura 4 - Plano de Cerro del Gentil

(C) según Canziani, 1992

Asimismo, en la descripción de un sector no monumental del Cerro del Gentil Canziani (1992: 106) señala que:

De otro lado, este sitio presenta en los alrededores, al sur y al este del montículo mayor una acumulación inusual de piedras de campo que parecen corresponder

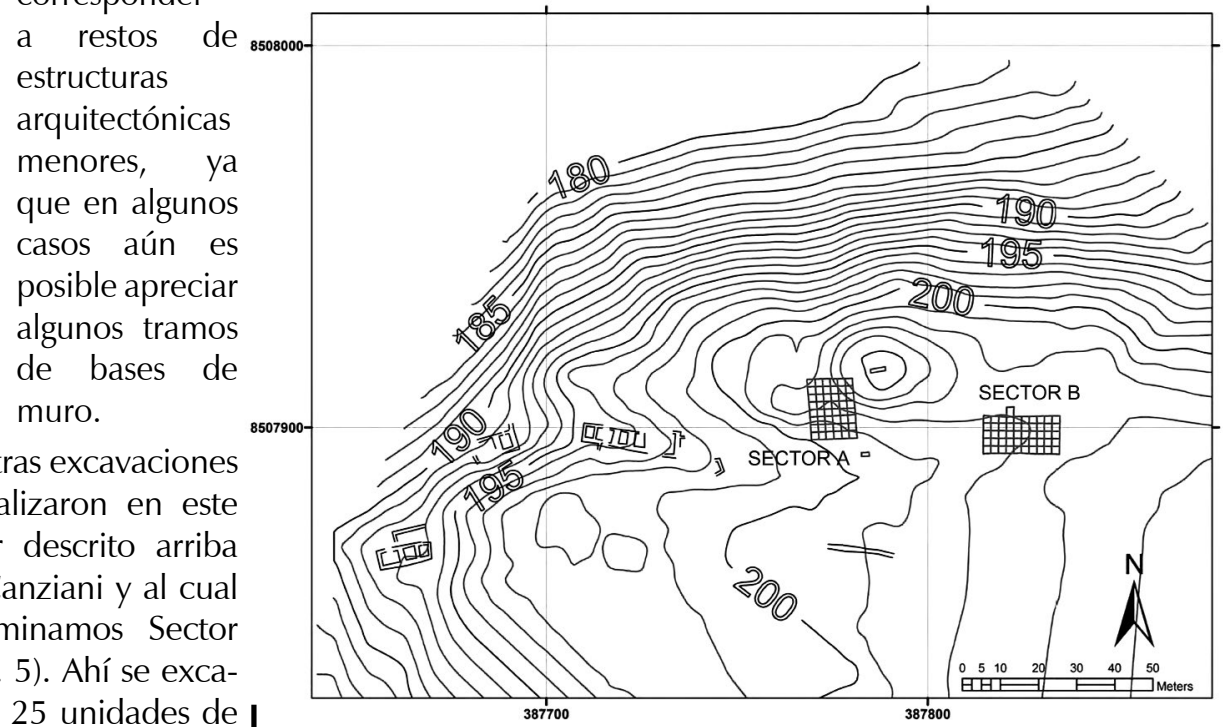
varon 25 unidades de $2 \mathrm{~m}^{2}$, lo cual nos dio Figura 5 - Plano de las excavaciones de 2012 un total de $100 \mathrm{~m}^{2}$ de (C) Programa arqueológico Chincha 


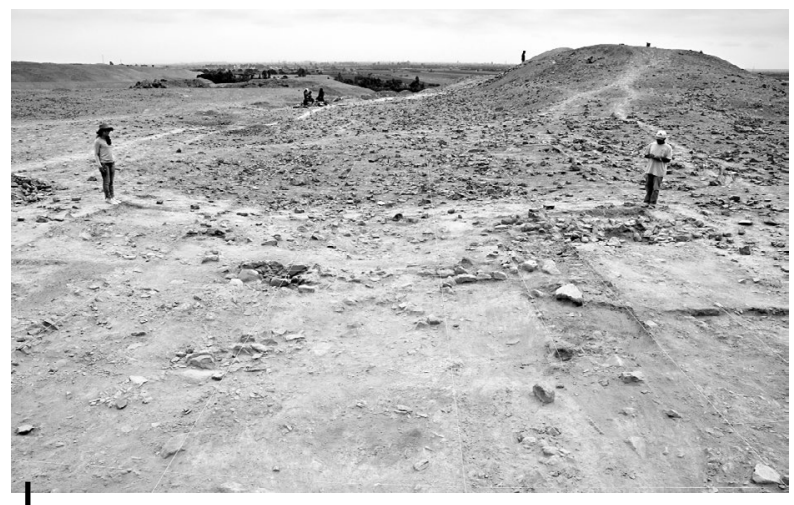

Figura 6 - Vista de la excavación del sector $B$ durante la temporada 2012

(C) Henry Tantaleán exposición de estructuras, rasgos arqueológicos y material cerámico a gran escala (fig. 6). La excavación de este sector expuso estructuras arquitectónicas rectangulares hechas con piedra de campo y barro y gran cantidad de desechos, especialmente de cerámica de tipo y uso doméstico, asociados con los pisos y muros excavados. El análisis de la arquitectura y los materiales asociados ha posibilitado la definición de este sector como un espacio doméstico relacionado con la cerámica de estilo Carmen (Pérez, 2012).

\section{EL SITIO ARQUEOLÓGICO DE PAMPA DEL GENTIL (PV.57-64)}

Este sitio se encuentra ubicado aproximadamente $400 \mathrm{~m}$ al suroeste del sitio de Cerro del Gentil y a unos 1500 metros al este del pueblo moderno de El Carmen (fig. 2). Se extiende en el margen de la terraza aluvial que se eleva del área del valle irrigado. Sobre esta área se extiende una concentración de recintos rectangulares de tamaños diferentes que alcanzan un área total de unas 3,5 ha (fig. 7). Según Canziani (1992; 2009: 152), el sitio tiende a asumir un patrón ortogonal, pero no corresponde a un asentamiento planificado sino que, más bien, es el producto de una progresiva agregación de construcciones y superposiciones arquitectónicas (fig. 8).

Wallace (1971: 50), registró y presentó un inventario de yacimientos arqueológicos bastante completo de los valles de Chincha, donde incluye el sitio de Pampa del Gentil (PV 57-64), describiéndolo de esta manera:

Extensas áreas con piedras de campo quebradas, en patrones que podrían indicar estructuras de un sitio de habitación. En algunos lugares las paredes son visibles, incluyendo una de adobes hemisféricos. La delimitación de los cuartos y del patrón de construcción es difícil de establecer; hay una pequeña plaza en un área, mientras que el resto es un aglomerado de construcciones. En el límite norte del sitio, a lo largo del borde de la estribación, hay muchas chullpas rectangulares (más o menos 20), en varios grupos, ninguna aislada, pero sin patrón generalizado. El sitio continua sobre el borde de la estribación en sus lados norte y sur.

Por su parte, Leonid Velarde (1998: 180) señala que la extensión del sitio Pampa del Gentil es de aproximadamente tres hectáreas de estructuras con un patrón de construcción sectorizado con espacios habitacionales con probables áreas públicas:

[...] creemos que de acuerdo a los elementos encontrados en el sitio es una aldea con áreas bien definidas de actividades públicas y domésticas, 


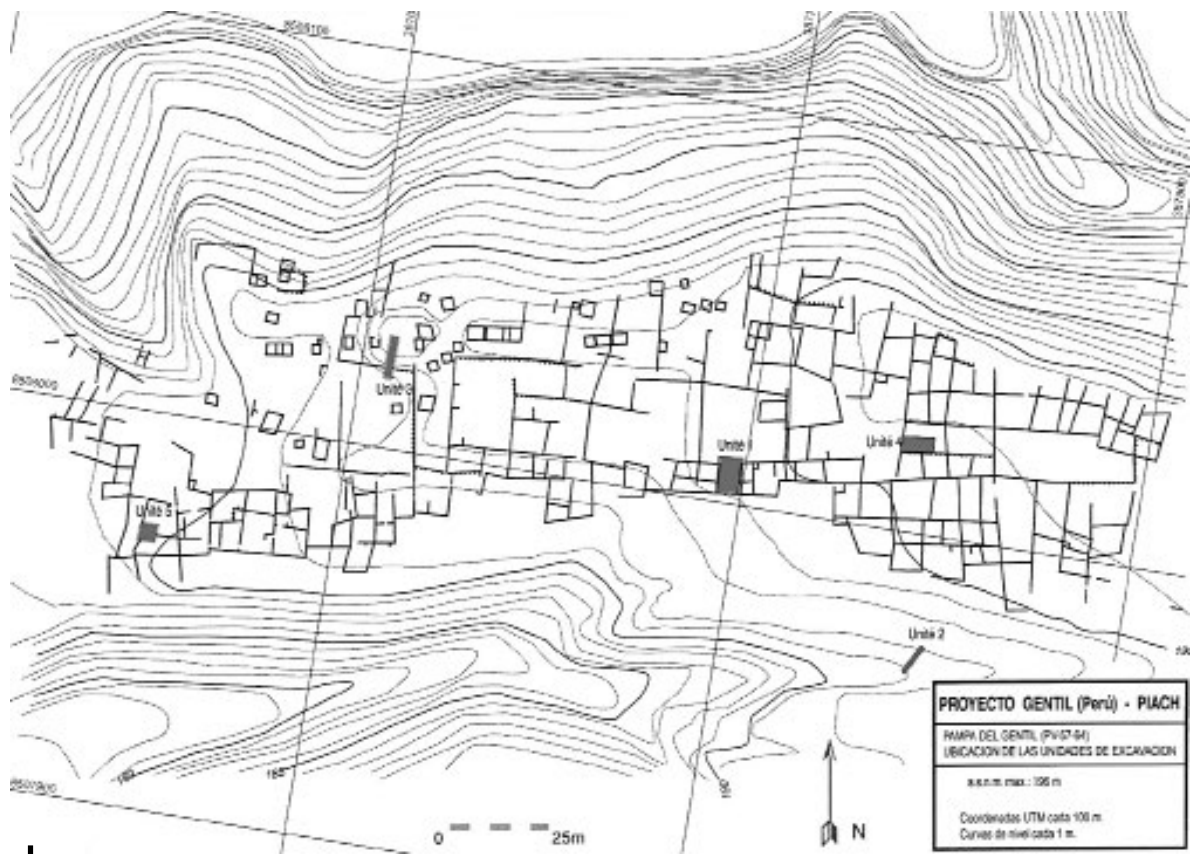

Figura 7 - Plano del sitio de Pampa del Gentil

(C) Leonid Velarde, 2006: fig. 5

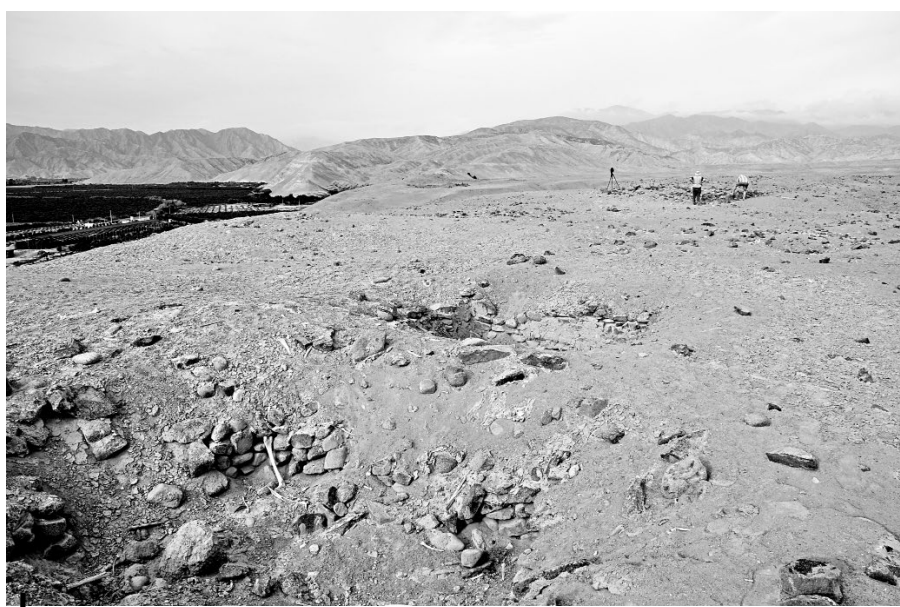

Figura 8 - Vista general del sitio Pampa del Gentil

(C) Henry Tantaleán sin estructuras monumentales ni notables edificios públicos (administrativos o seculares).

Asimismo, Velarde (2006) realizó excavaciones en el sitio en los años 1999 y 2001. Se realizaron 5 unidades de excavación, las cuales comprometieron varios sectores del sitio (fig. 7). De especial interés para nosotros es la excavación de la Unidad 1 donde se pudo exponer una estructura arquitectónica rectangular («recinto de habitación») asociada a cerámica de estilo Carmen y Campana (Velarde, 2006: 174, fig. 6). Dicha forma y técnica de construir los recintos guarda mucha semejanza con los restos de recintos excavados por nosotros en el Sector B de Cerro del Gentil (Pérez, 2012).

Adicionalmente, la excavación de Velarde de la Unidad 3 fue realizada en la parte sur de un montículo de unos 2 metros de altura y ayudó a identificar muros 
de contención de rellenos de tierra. De acuerdo con los contextos encontrados por Velarde, la base sur del montículo era un área de actividad pública con pisos preparados (Velarde, 2006: 177-179). El pequeño montículo de Pampa del Gentil contuvo diferentes estilos cerámicos (Chongos, Campana, Carmen) aunque predomina notablemente la cerámica de estilo Carmen. Gracias a sus hallazgos, Velarde (2006: 171) se ratifica en la propuesta de que Pampa del Gentil fue una aldea debido a las características principales de las estructuras arquitectónicas y los materiales asociados y que fue ocupada durante el periodo de los Desarrollos

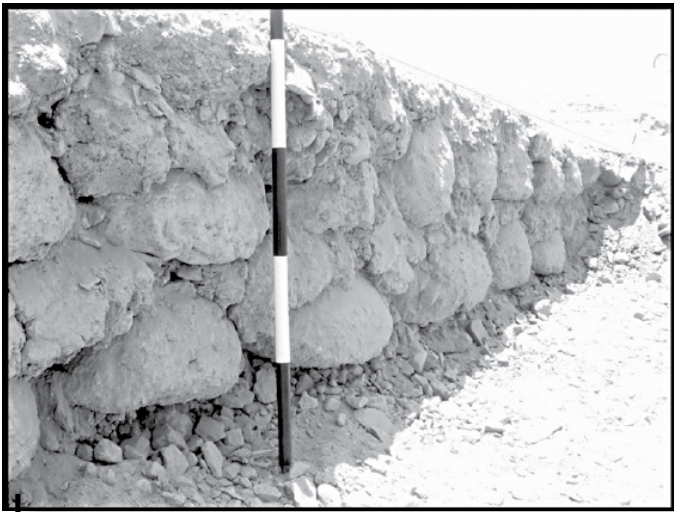

Figura 9 - Vista del muro con adobes de estilo Carmen en montículo de Pampa del Gentil

(c) Abel Fernández

Regionales Tempranos.

La excavación que realizamos en Pampa del Gentil se ubicó en la cima del montículo que también había sido excavado por Velarde (Unidad 3). Allí se encontró una gran concentración de desechos conteniendo fragmentos cerámicos y restos de consumo de plantas y animales. Asimismo, se expuso un muro con adobes típicos Carmen (Peters, 1997; Velarde, 2006) (fig. 9).

\section{EL ESTILO CERÁMICO CARMEN: ANTECEDENTES DE INVESTIGACIÓN}

Para contextualizar nuestra discusión de los materiales relacionados con el estilo Carmen, antes deberemos revisar los antecedentes de su investigación. Lo que se conoce como el estilo cerámico Carmen es un conjunto material poco conocido cuantitativa y cualitativamente; en general, ha sido relacionado con el estilo cerámico Nasca, específicamente en sus Fases Nasca 3 y 4 (Silverman \& Proulx, 2002: 251; Proulx, 2006: 197) (fig. 10). A su vez, la definición del estilo Nasca se deriva de los trabajos pioneros de Max Uhle (1924) realizados entre 1900 y 1905, por encargo de la Universidad de California en las áreas de Chincha y, posteriormente, en Nasca y Palpa. La contribución principal de Max Uhle fue el reconocimiento de la cerámica Nasca y su incorporación cronológica al horizonte estilístico que constituyó la base para las investigaciones sucesivas. También entendió que estaba frente a una sociedad que llegó a influir a una extensa área de la costa sur. La trascendencia y continuidad del trabajo de Uhle se ve reflejada en las posteriores publicaciones de Alfred Kroeber \& William Duncan Strong (1924), William Duncan Strong (1957), Donald Proulx (1968; 2006; 2008) y Helaine Silverman (2002), entre otros.

Con respecto a la cronología absoluta vinculada con la Fase Nasca 3, Strong (1957: 46) menciona tempranamente una muestra de carbono 14 que adjudica una antigüedad de $336 \pm 200$ d. C. asociada a un entierro de Cahuachi correspondiente a dicha fase (Muestra L-335G, N-4, Entierro de Cahuachi 39). 


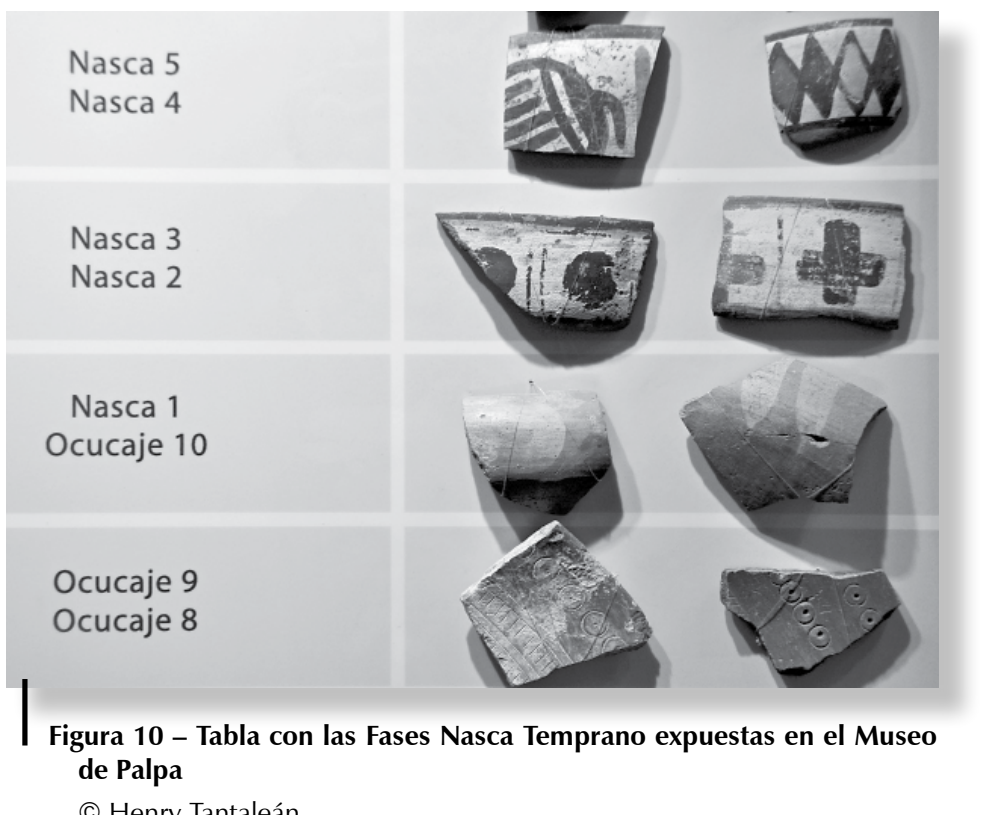

Asimismo, en las expediciones de la Universidad de Columbia (1952), se realizaron excavaciones en Cahuachi, habiéndose encontrado restos de cerámica Nasca 1 («Proto-Nasca») en estratificación, encima de Paracas y debajo de la fase 2. También se encontraron restos de la Fase 2 y 3 , en su correspondencia estratigráfica sobre Nasca 1. Antes de la expedición organizada por la Universidad de Columbia en Cahuachi, no se disponía literalmente de datos para la fase 2. Luego, Dawson encontró vasijas adicionales de Nasca 2 en los museos y colecciones particulares. En ese momento, el material asociado a Nasca 3 era muy escaso (Menzel, 1971: 63)3. En 1957 se inició un proyecto de investigación de tres años de duración, auspiciado por el programa Fullbright. Así, en 1957, Dwight Wallace realizó estudios en el valle de Chincha, luego en 1958 en Ica, Cañete, Mala y Asia. En el año 1959 inició un proyecto destinado a determinar las nuevas secuencias de los estilos Paracas y Nasca. Uno de sus aportes fue la identificación y caracterización del estilo Carmen en Chincha y Cañete. Wallace nos señala también que en el Intermedio Temprano se reconoce la influencia del prestigio de la zona de Ica-Nasca en los valles de Cañete, Chincha y Pisco, los cuales presentan variantes muy cercanas relacionadas con la fase Nasca 3 de Ica y Nasca. La influencia de Nasca 3 se apreciaría en la forma y decoración de la cerámica, particularmente en el énfasis puesto en los dibujos geométricos (Menzel, 1971: 121).

Siempre siguiendo a Wallace, es interesante notar que las influencias de Nasca 3 aparecen tanto en la forma como en el diseño en los valles de Chincha y Cañete.

3 La escasez de ejemplos de esta fase se ha remediado con los trabajos de Proulx (2006: 34) quien llega a contar 1431 especímenes que se pueden vincular con esta fase. 
Según Menzel (1971: 122):

Wallace identificó los estilos en los yacimientos de Dos Palmas en Pisco (PV.58-3), El Carmen en Chincha (PV.57-64) [Pampa del Gentil], y fragmentos procedentes de La Quebrada en Cañete. Él distingue la variante de Chincha y Cañete con el nombre de Carmen, y la variante de Pisco como Dos Palmas. También encontró restos de estilo Carmen en once sitios adicionales del valle de Chincha y restos de Dos Palmas en seis asentamientos adicionales del valle de Pisco. (Entre corchetes nuestro).

Para Wallace (1959: 21) en el estilo Carmen:

El rasgo más característico son líneas diagonales de color rojo y blanco, alternadas sobre una base negra en los exteriores de platos de paredes bajas.

Asimismo, también señala que los cuencos son los tipos decorados más recurrentes, semejantes, aunque con ligeras variantes, a los de la Fase Nasca 3.

Por su parte y en base a los trabajos de Wallace, Menzel (1971: 122) señala que:

Hay cuencos proporcionalmente bajos, de poca profundidad y con el diseño principal en el interior, al mismo tiempo que se encuentran otros de lado más alto con la decoración en el exterior.

Y con respecto a la variedad de colores:

Mientras los colores más comunes en el estilo Carmen son los fondos negros o rojos y rayas rojas y blancas sobre negro, Wallace coloca otros en orden descendentes según la frecuencia con que aparecen y que son: morado naranja, amarillo y gris (Menzel, 1971: 122-123).

Adicionalmente, asociados a los colores negros, morados y gris, en el estilo Carmen se observan pigmentos con partículas plateadas similares a los de la cerámica Nasca. Menzel (1971: 123) siempre basándose en Dawson, señala que los pigmentos iridiscentes y luminosos tienen su origen en el estilo Nasca 3, presentes en el valle de Chincha. Señala, además, que estos pigmentos desaparecieron después de la extinción de la fase Carmen. Los pigmentos oscuros con partículas plateadas se elaboran con un óxido duro llamado hematita especularia, el cual se encuentra en forma cristalina y tiene un color natural morado oscuro, lo que le da el brillo plateado a la cerámica. Para obtener otros colores se añaden otros pigmentos necesarios (Menzel, 1971: 123). Adicionalmente, Menzel (1971), sintetiza la información sobre la identificación de los estilos de cerámica y sus relaciones cronológicas de los patrones culturales en el valle de Chincha, Cañete (Fase Carmen) y Pisco.

Dos décadas después, Leonid Velarde (1993: 58) indica que la distribución del estilo cerámico Carmen estaría restringida prácticamente a la margen izquierda del valle, hasta unos 22 kilómetros alejados del mar, afirmando que la ocupación del estilo asociado Carmen es más importante de lo que fue aceptada hasta ese momento, identificando aproximadamente 39 sitios con elementos «Carmen», aunque 8 de ellos requerían confirmación mediante un mayor trabajo de campo. Más adelante, Velarde (1999) señala que el estilo Carmen se diferencia 
notablemente del estilo Nasca en su tratamiento iconográfico ya que el estilo Nasca en las fases 3 y 4 utiliza elementos recurrentes bastante naturalistas (peces, aves, frutos, etc.) y seres míticos (también ver Proulx, 2006). En el caso del estilo Carmen, Velarde encuentra una lejana semejanza con el estilo Nazca pues, a lo mucho, se han encontrado algunos diseños serpentiformes exclusivamente en cuencos. Esta marcada diferencia en la decoración le resulta suficiente a Velarde (1999: 70) para proponer que se trata de un estilo local e independiente diferenciado de Nasca. En un trabajo posterior, Velarde define de la siguiente manera la cerámica al estilo-fase Carmen:

A grandes rasgos podemos decir que esta fase se define principalmente por un tipo de decoración, que aparece sobre el exterior de cuencos abiertos, que consiste en líneas diagonales rojo y blanco sobre fondo negro. En el interior, sobre el fondo de la vasija, puede haber un panel circular con motivos abstractos todo generalmente sobre rojo o negro (Velarde, 2006: 171).

Otras formas de cerámica características del estilo Carmen son unos boles (vasijas semicerradas), vasos y ollas. En las ollas, Wallace encontró una decoración de protuberancias sobre el tercio superior del cuerpo y estas ollas presentan, por lo general, un labio reforzado, asociado solamente al estilo Carmen. Las vasijas abiertas (los cuencos, vasos e, incluso, los boles) están todos decorados polícromamente y, por sus acabados, podríamos llamarla vajilla fina (Velarde, 1998).

Fuera del valle de Chincha, Helaine Silverman (1997) trabajó en el sitio de Alto del Molino ubicado en el valle bajo de Pisco, al sur de Chincha. Este sitio presenta ocupaciones de la fase «Chongos» (Periodo Intermedio Temprano 1) y Carmen. Silverman (1997) excavó una serie de estructuras de carácter habitacional y contextos funerarios pertenecientes a la Época 1 del Periodo Intermedio Temprano. Para el Periodo Intermedio Temprano 3, registró arquitectura pública con ofrendas de entierros humanos (Silverman, 1997). Por su parte, en el mismo valle de Pisco, Ann Peters (1997: 553-558) reconoce al estilo Carmen dentro de su material excavado en el sitio de Pachinga.

\section{SOBRE LA CRONOLOGÍA ABSOLUTA ASOCIADA AL ESTILO CARMEN}

De acuerdo con lo que sabemos, el estilo cerámico Carmen no posee fechados absolutos tanto para los sitios asociados con este estilo en el valle de Chincha como en el de Pisco. Como vimos arriba, fueron los trabajos de Wallace (1959) y Menzel (1971) los que asociaron inicialmente al estilo Carmen con la fase Nasca 3 y 4 . Sin embargo, los fechados absolutos para Nasca, en sí mismos presentan problemas técnicos debido a que anteriormente muchos de ellos fueron elaborados sobre la base de métodos que presentaban errores.

Así, Velarde (1999: 70) resalta que para las fases Nasca 1 a Nasca 4 el rango de variabilidad es muy grande y la proporción de muestras es pequeña. Posteriormente se han realizado nuevos fechados para «Nasca Temprano»; entre ellos, podríamos 
referirnos a los generados por Kevin Vaughn $(2004:$ 72, 76) en el sitio de Marcaya. Este sitio está ubicado en la ladera norte del valle del río Tierras Blancas, en una suave pendiente, a unos 16 kilómetros arriba de la moderna ciudad de Nazca. En diferentes patios de este sitio se evidenció cerámica asociada a las fases Nasca 3 y Nasca 4. Las fechas de radiocarbono asociadas a estas muestran un período relativamente corto de tiempo. Vaughn ofrece 3 fechados realizados en materiales Cuadro 1 - Fechados calibrados y no calibrados de los sitios Marcaya y Upanca para Nasca
Temprano

\begin{tabular}{|c|c|c|c|}
\hline \multicolumn{4}{|c|}{ NASCA TEMPRANO } \\
\hline FECHADOS & SITIO & $\begin{array}{c}\text { NO } \\
\text { CALIBRADO }\end{array}$ & CALIBRADO \\
\hline \multirow[t]{3}{*}{ Kevin Vaughn (2004) } & \multirow[t]{3}{*}{ Marcaya } & $1720 \pm 40$ B.P. & Cal A.D. $240-420$ \\
\hline & & $1630 \pm 40$ B.P. & Cal A.D. $370-540$ \\
\hline & & $1760 \pm 60$ B.P. & Cal A.D. $130-420$ \\
\hline Vaughn \& Linares (2006) & Upanca & $1740 \pm 70$ B.P. & Cal A.D. $120-435$ \\
\hline
\end{tabular}

de carbón para el sitio de Marcaya: (1720 \pm 40 B.P.) Cal A.D. 240-420, (1630 \pm 40 B.P.) Cal A.D.370-540 (1760 \pm 60 B.P.) A.D. $130-420$ (ver cuadro 1).

Otros trabajos realizados por Vaughn \& Linares $(2006: 598,602)$ en el sitio de Upanca, ubicado en la margen norte del valle del río Tambo Quemado, en el departamento de Ayacucho, a unos $30 \mathrm{~km}$ aguas arriba de la ciudad de Nasca, representarían una ocupación «Nasca Temprano», fundamentada en la cerámica recuperada en sus excavaciones. Una muestra de carbón asociada con cerámica en el Sector III, Estructura 6 (III-6) se tradujo en una fecha radiocarbónica de $1740 \pm 70$ B.P., Cal A.D. 120-435, lo que confirma esta temprana ocupación (ver cuadro 1).

Por su parte, en Cahuachi, Aïcha Bachir y Daniel Llanos (2006) reportan una serie de fechados de C14 tomados de Ziołkowski et al. (1994). La mayoría de esos fechados corresponden a muestras asociadas con cerámica de la Fase Nasca 3. Estos fechados presentan un rango que va desde los $1400 \pm 60$ B.P. hasta los $1760 \pm 50$ B.P. Es importante resaltar que estos fechados se correlacionan temporalmente con los de Marcaya y Upanca.

Por su parte, el equipo del «Proyecto Arqueológico Palpa» (Unkel et al., 2012) reporta un gran número de muestras orgánicas de contextos estratigráficos claramente definidos en los asentamientos de diferentes periodos en la región de 
Palpa, departamento de Ica. Con ello, nos presentan un panorama actualizado y ampliado de la cronología, que incluye nuevas dataciones de acuerdo con los últimos avances en la calibración y modelos estadísticos. Los materiales orgánicos se obtuvieron a partir de las excavaciones de Markus Reindel y Johny Isla desde 1997, con un total de 115 muestras de C14, que incluyen madera y carbón, de las cuales 7 muestras corresponden al período «Nasca Temprano» (80-300 cal AD), procedentes del sitio de Los Molinos (Unkel et al., 2012: 2295-2302).

Sobre la base de los datos mostrados anteriormente y siguiendo la correlación establecida entre Carmen y Nasca 3 y 4 por los diferentes investigadores arriba mencionados, los nuevos fechados colocarían al estilo Carmen entre los años 200 y 400 d. C., resultando cronológicamente posterior a lo establecido originalmente por Wallace. Así, para efectos de nuestra investigación, utilizaremos los nuevos fechados absolutos, como referencia, hasta la espera de los resultados de las nuevas muestras obtenidas en Nasca y en Chincha.

\section{EL ESTILO CERÁMICO CARMEN EN CERRO DEL GENTIL Y PAMPA DEL GENTIL}

En nuestras excavaciones en el Sector B del sitio de Cerro del Gentil, se recolectaron 2398 fragmentos (ver cuadro 2). Sin embargo, solo se han analizado los fragmentos diagnósticos (bordes y cuerpos decorados) que equivalen a 138 fragmentos (Pérez, 2012). Es necesario resaltar que la distribución de las características y cantidades de los fragmentos de la cerámica en Cerro del Gentil, según la procedencia de los contextos (estructura circular, área con arquitectura, pisos, depósito, rellenos de basura), nos indica que la mayoría de los fragmentos proceden de los pisos y áreas con arquitectura asociadas a una gran cantidad de restos de carbón, maní, maíz y frejol (Pérez, 2012).

Para el caso de la excavación del pequeño montículo del sitio de Pampa del Gentil, se han analizado 110 fragmentos diagnósticos de un total de 250 fragmentos (ver cuadro 2). Estos fragmentos estaban asociados a un muro arquitectónico con material constructivo de adobes semiesféricos y restos de basura doméstica, que incluían vértebras de camélidos, restos malacológicos y botánicos (fig. 9).

Cuadro 2 - Tabla detallada de los estilos identificados y las cantidades de los fragmentos por estilo en Cerro del Gentil y Pampa del Gentil

\begin{tabular}{|c|c|c|c|c|c|}
\hline \multirow{3}{*}{ SITIOS } & \multicolumn{5}{|c|}{ ESTILOS } \\
\hline & \multicolumn{3}{|c|}{$\begin{array}{l}\text { FRAGMENTOS } \\
\text { DIAGNÓSTICOS }\end{array}$} & \multirow{2}{*}{$\begin{array}{c}\text { FRAGMENTOS NO } \\
\text { DIAGNÓSTICOS } \\
\text { CANTIDAD }\end{array}$} & \multirow{2}{*}{ TOTAL } \\
\hline & CAMPANA & CARMEN & OTROS & & \\
\hline CERRO DEL GENTIL & 4 & 113 & 21 & 2260 & 2398 \\
\hline PAMPA DEL GENTIL & 4 & 99 & 7 & 140 & 250 \\
\hline TOTAL & 8 & 212 & 28 & 2400 & 2648 \\
\hline
\end{tabular}


De los 138 fragmentos analizados del Sector B de Cerro del Gentil, 113 corresponden al estilo Carmen (82\%) y 4 fragmentos al estilo Campana (3\%) (ver fig. 11). Por otra parte, los resultados de la excavación en Pampa del Gentil indican que 99 fragmentos pertenecen al estilo Carmen (90\%) y solo 4 fragmentos al estilo Campana $(6,4 \%)$. Por lo tanto queda claro, cuantitativamente hablando, que el estilo Carmen es predominante en ambas muestras y en los sectores arqueológicos investigados.
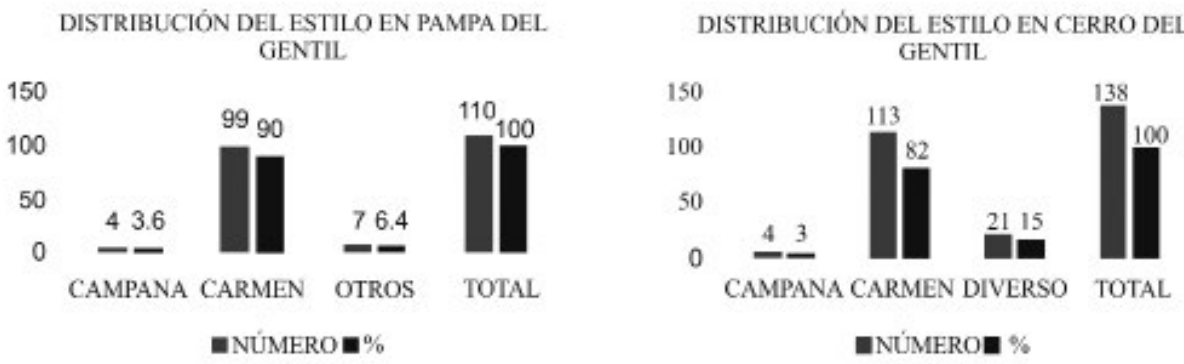

Figura 11 - Cantidad y porcentaje de los fragmentos de cerámica según el estilo (Carmen y Campana) en Cerro del Gentil y Pampa del Gentil

Por otro lado, la clasificación de las formas de la cerámica de estilo Carmen se redujo a cuatro tipos principales: cuencos, platos, ollas y cántaros. Entre las formas representativas, encontradas en Cerro del Gentil, 52,2 \% corresponde a la forma de cuenco y el $2,2 \%$ corresponde a la forma de platos (ver fig. 12). Para el sitio de Pampa del Gentil, el 19\% corresponde a la forma de cuencos, seguido por la forma plato con el 2,2\% (ver fig. 12). Esto sugiere que el uso de las formas de cuencos y platos fue frecuente en el sitio. Asociadas a estas formas tenemos a las vasijas cerámicas sin decoración (ollas, cantaros) que también son cuantitativamente significativas, especialmente la forma olla.

Teniendo como base a los materiales encontrados en los sitios Cerro y Pampa de Gentil, se puede plantear que existieron sectores en ambos sitios que tuvieron

DISTRIBUCIÓN DE LA FORMA EN CERRO DEL GENTIL

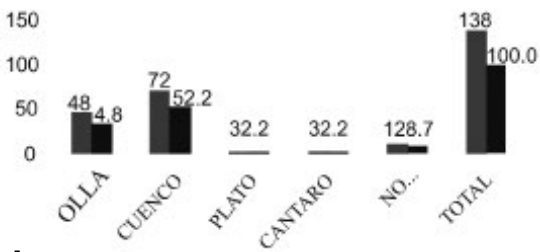

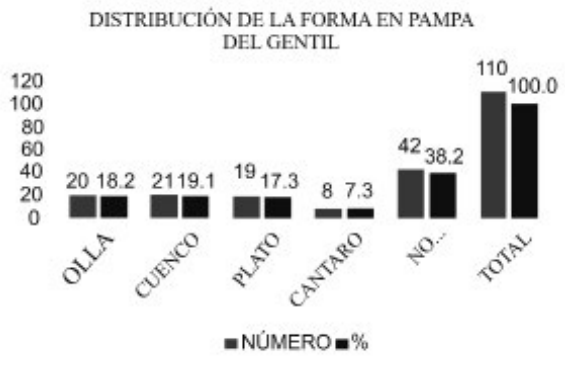

Figura 12 - Tabla detallada de las formas cerámicas identificadas en las muestras procedentes de Cerro del Gentil y Pampa del Gentil 
una preponderancia tanto cualitativa como cuantitativa del estilo Carmen, en contraste con la cerámica de estilo Campana.

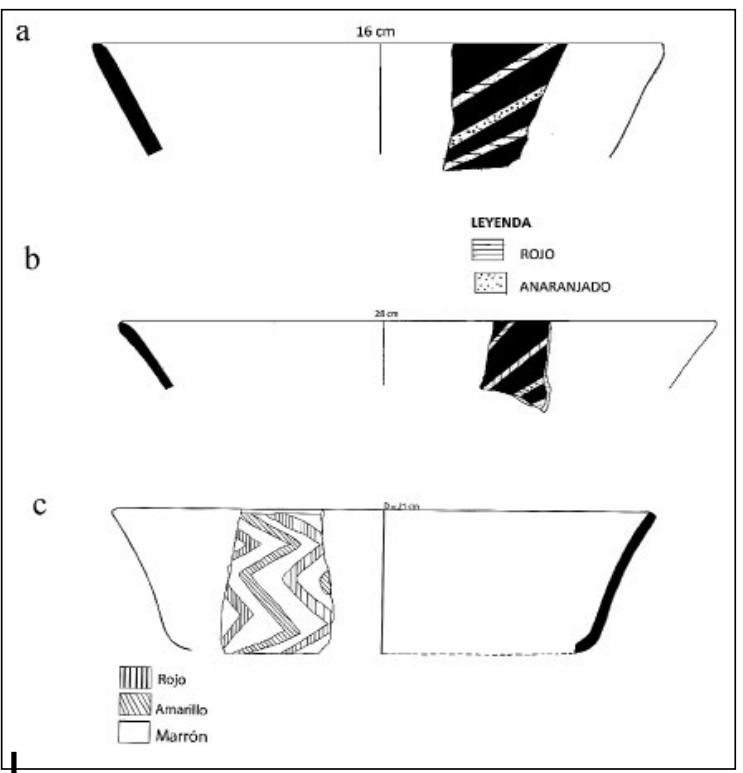

Figura 13 - Reconstrucción de tazones de estilo Carmen sobre la base de fragmentos, asociado al Sector A y B de Cerro del Gentil

(c) Programa Arqueológico Chincha
Como vimos anteriormente, la decoración que distingue al estilo Carmen consiste en una base de pintura negra o marrón oscuro en las vasijas, sobre la cual se pintan, principalmente, líneas diagonales rojas, amarillas y blancas (ver figs. 13, 15 y 16). Adicionalmente, en las excavaciones del sector B de Cerro del Gentil también se encontró un fragmento de tazón con decoración de líneas en zig-zag, sobre un fondo marrón oscuro (fig. 13c) similar a uno encontrado por Peters (1997: Fig. 7.45 e) en el sitio de Pachinga en el valle de Pisco. La decoración de los fragmentos cerámicos del estilo Campana encontrados en ambos sitios consiste, principalmente en que el borde del fragmento y parte del fondo de la vasija fueron pintados de negro (ver fig. 14c).

El análisis de la decoración de nuestra muestra de cerámica Carmen arroja una mayor variedad para el sitio de Pampa del Gentil, cuestión anteriormente advertida por Velarde (1999: 70):
... en Carmen son bastante abstractos predominando además de las líneas diagonales en rojo y blanco, unos diseños aserrados (iserpientes?), líneas con gancho y otros diseños geométricos, todos presente al interior de los cuencos.

Un ejemplo de este tipo de decoración corresponde a un cuenco de estilo Carmen encontrado en Pampa del Gentil. Este espécimen presentó una decoración en bandas precisas; bandas onduladas (rojas) que encierra a otra banda en forma ovalada (anaranjado) en cuyo interior hay una línea horizontal (blanca), todo sobre un fondo negro.

Nuestro análisis indica que la mayoría de las formas cerámicas con decoración son los cuencos (abiertos y cerrados) con base plana y en algunos casos semiconvexa del estilo cerámico Carmen. En todos los casos, los cuencos abiertos y los

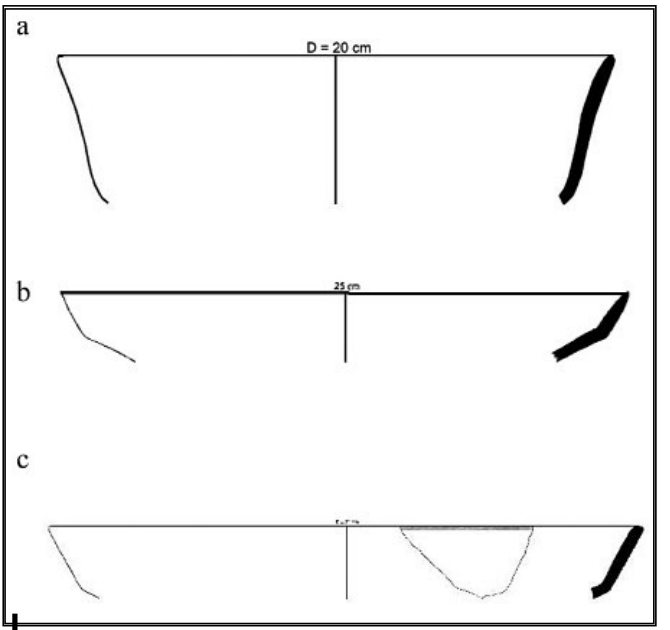

Figura 14 - Reconstrucción de tazón y plato de estilo Carmen (a y b) y Campana (c) sobre la base de fragmentos, asociados al Sector A y B de Cerro del Gentil

(C) Programa Arqueológico Chincha 
platos presentan diseños en la parte externa de líneas paralelas y diagonales, blancas y rojas, de 2 a $3 \mathrm{~mm}$, que se orientan de derecha a izquierda, iniciándose desde el encuentro de la base hasta el borde de la vasija, siempre en la pared externa del tazón. Estos diseños cubren toda la pared externa, sobre un fondo completamente negro. Algunos platos también tienen decoración en la base interna y describen un círculo concéntrico, delimitado con una banda de color blanca, en cuyo interior hay líneas rojas paralelas sobre un fondo negro. Velarde (1999: 69) define esta forma de decoración como un panel circular dentro del cual existen diseños estilizados $y$, en algunos casos, se extiende sobre la pared interna de la vasija.

Los cuencos cerrados también son formas recurrentes del estilo cerámico Carmen, caracterizados por presentar diseños solo en la parte externa. Los diseños están en la región superior y central del cuerpo de la vasija cerámica (en ningún caso en el inferior), delimitados por bandas blancas horizontales de 2 a $3 \mathrm{~mm}$ en promedio que recorren todo el contorno de la vasija. El diseño presenta líneas paralelas y diagonales blancas y rojas, de 2 a $3 \mathrm{~mm}$, que se orientan de derecha a izquierda, iniciándose en el límite inferior de la banda blanca, sobre un fondo negro. En todos los casos observados, en las zonas sin diseño sobresale el color anaranjado (ver fig. 16 a, b, c, d).

Asimismo, las ollas sin cuello y los cántaros son las formas más significativas de la cerámica sin decoración del estilo Carmen. Adicionalmente, en casi todos los fragmentos de las ollas que correspondían a la base y al cuerpo, en lo que vendría a ser la parte externa de la vasija, se reconocieron manchas de quema y rastros de hollín. También, entre los fragmentos cerámicos pertenecientes a estas ollas se evidenciaron algunos que presentaban una protuberancia típica de la cerámica doméstica del estilo Carmen (ver figs. 17 y 18).

En la muestra analizada, el tratamiento superficial más representativo de la cerámica del estilo Carmen es el alisado. Esto nos puede revelar que hubo una preocupación especial en la elaboración del acabado de la superficie de la cerámica. Cabe mencionar que los tratamientos especializados del pulido y bruñido fueron 


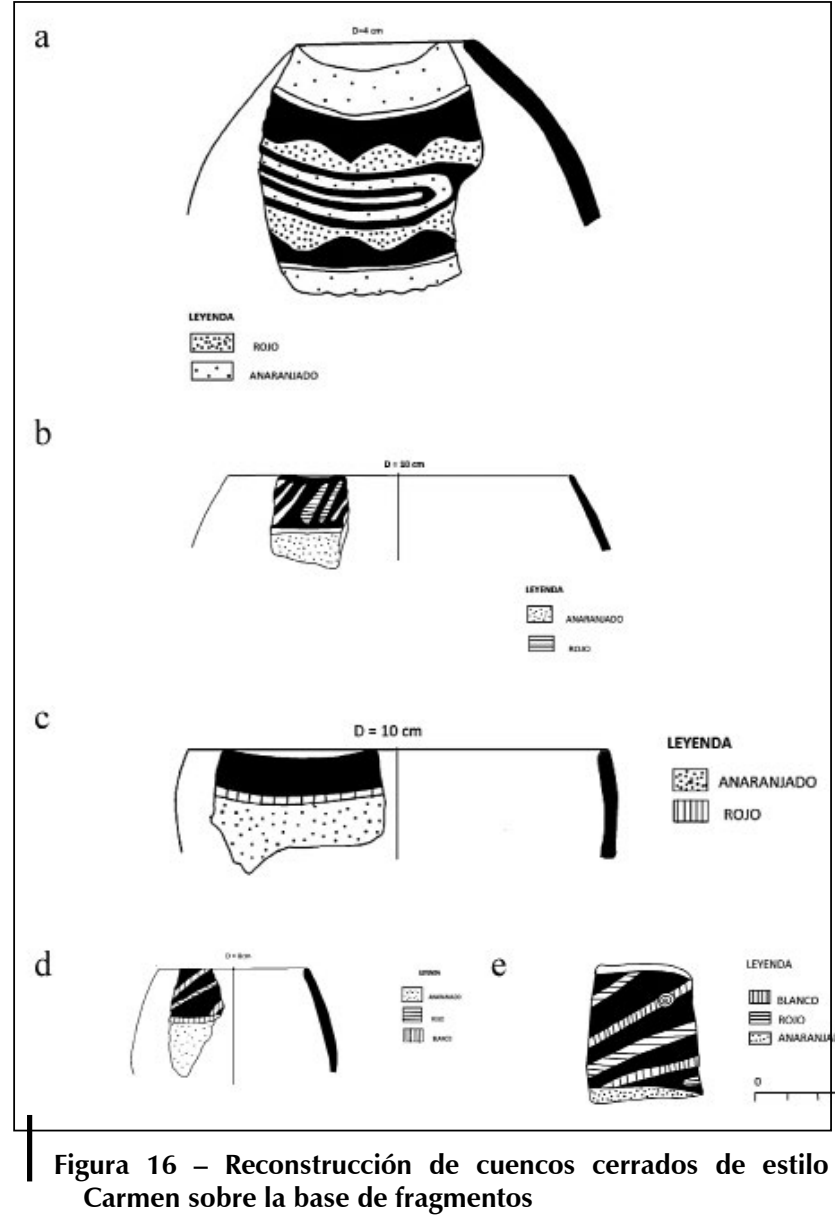

Estos fragmentos estaban asociados al muro del pequeño montículo de Pampa del Gentil

(c) Programa Arqueológico Chincha

significativos aunque en menor cantidad. A diferencia de las cerámicas llanas, aquellas provistas de diseños fueron mejor elaboradas con respecto al acabado.

Por otra parte, la atmósfera de cocción más común en la muestra analizada fue la del tipo oxidante. La cocción abierta resulta perfectamente adecuada para cocer muchas vasijas y tiene además la ventaja de ser más manejable por el ceramista. Para el futuro esperamos completar los estudios de la composición química de las arcillas y desgrasantes empleados para establecer si las vasijas fueron producidas localmente o fuera de esta zona del valle.

Así pues, sobre la base de los hallazgos en los sitios Cerro y Pampa del Gentil, los rasgos formales del estilo cerámico Carmen reportados nos permiten establecer las características estilísticas y morfofuncionales de la cerámica, asociadas a la 


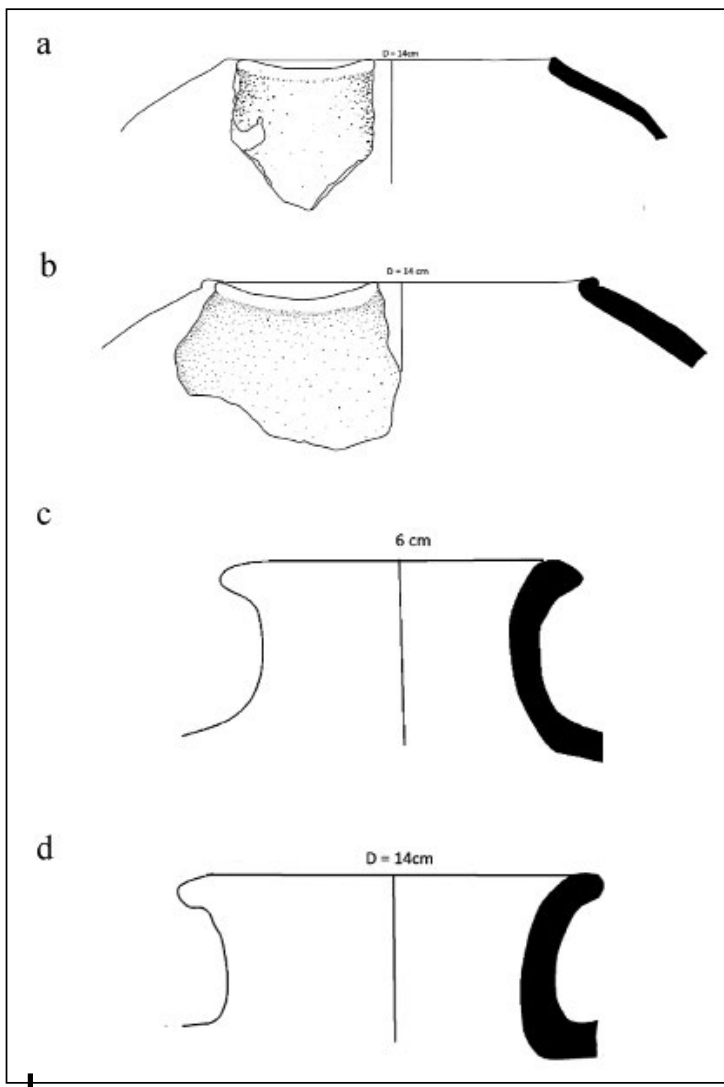

a

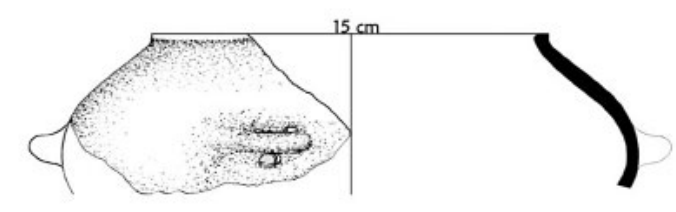

b

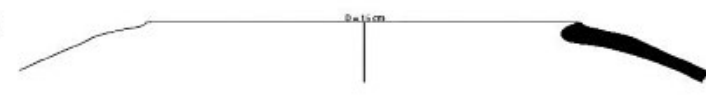

$\mathrm{c}$

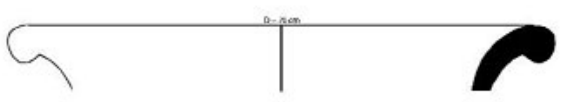

d

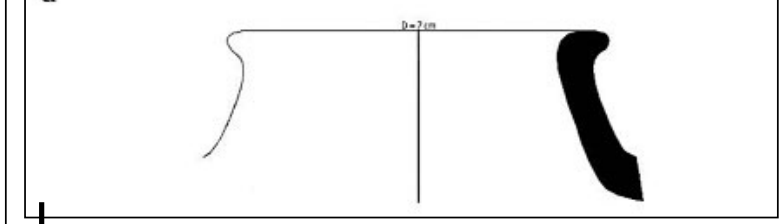

Figura 18 - Reconstrucción de ollas sin cuello (a y b) y cántaros (b y c) asociados al Sector B en Cerro del Gentil

(C) Programa Arqueológico Chincha

Figura 17 - Reconstrucción de ollas sin cuello (a y b) y cántaros (b y c) asociados al muro del montículo pequeño de Pampa del Gentil

(C) Programa Arqueológico Chincha

arquitectura. De acuerdo con lo que sabemos, los rasgos particulares del estilo cerámico Carmen presentes en ambos sitios son idénticos a otros del valle de Chincha a un nivel morfológico y decorativo e, incluso, tienen mucha similitud con especímenes recuperados en el valle de Pisco y en la misma península de Paracas.

\section{DISCUSIÓN Y SÍNTESIS}

En la costa sur del Perú durante el periodo «Formativo Medio» y Superior (circa 800200 a. C.) se desarrolló una sociedad relacionada con la cerámica de estilo Paracas, la cual realizó grandiosas construcciones arquitectónicas en el valle de Chincha, tales como Huaca Santa Rosa, Huaca Alvarado, Huaca La Cumbe, Huaca San Pablo, Huaca Soto o Huaca Torres (Canziani, 1992; Lumbreras, 2008). Seguidamente, una ocupación de nuevos sitios y, en algunos casos sobre sitios Paracas, fue realizada por grupos humanos vinculados a un estilo cerámico denominado como «Topará» 
(Wallace, 1986; Peters, 1997; Silva \& García, 1997). Posteriormente, en el mismo valle, se establecieron una serie de asentamientos vinculados al estilo cerámico Carmen (circa 200-400 d. C.), al cual no se le ha atribuido ningún complejo arqueológico de grandes proporciones similares a los Paracas. Por el contrario, durante esta ocupación humana del valle se reutilizan muchos sitios Paracas y Topará, como Huaca San Pablo o, como hemos visto, en los mismos Cerro del Gentil y Pampa del Gentil (Velarde, 1998: 180).

Los trabajos de Wallace en el valle de Chincha desde la década de 1950, han logrado identificar y caracterizar al estilo Carmen y correlacionarlo con las fases del estilo Nasca (Silverman \& Proulx, 2002; Proulx, 2006). Posteriormente, Velarde $(1993 ; 1999 ; 2006)$ ha intentado darle una explicación de carácter social a este estilo cerámico. Según Velarde, el grupo humano vinculado con esta cerámica mantuvo relaciones sociales con el fenómeno social Nasca ubicado hacia el sur, aunque con una lejana semejanza. En efecto, su similitud solo se limita a patrones de formas y decoración cerámicas muy generales, una perspectiva que también es compartida por Silverman y Proulx (Silverman \& Proulx, 2002: 83; Proulx, 2006: 7).

Al tener en consideración los antecedentes de la cerámica de estilo Carmen y al contrastar la evidencia en el campo y laboratorio, nos aproximamos a definir el estilo Carmen como un elemento principal de la ocupación humana de carácter doméstico que habrían tenido estos sitios después del momento Paracas y Topará. A nivel ceramográfico, la alta concentración de ollas, cántaros y cuencos nos ayuda a corroborar dicha propuesta.

Nuestras excavaciones en el Sector B de Cerro del Gentil nos han permitido comprobar la existencia de estructuras domésticas formales y/o permanentes, vinculadas, casi exclusivamente al estilo Carmen, lo que nos demuestra que este sector solo tuvo una ocupación asociada a dicho estilo (Pérez, 2012). Por tanto, queda descartada la hipótesis de que se trataba de un sector residencial asociado a Paracas (Canziani, 1992: 106). De hecho, no existen evidencias de una ocupación permanente Paracas en el sitio de Cerro del Gentil, más allá del edificio piramidal y un pequeño montículo al suroeste de este edificio.

Por otra parte, los hallazgos en el montículo de Pampa del Gentil, también asociados a espacios domésticos, demuestran la existencia de una mayor variedad y densidad de elementos recurrentes de diseños de estilo Carmen ya que no solo hay representaciones geométricas clásicas, sobre un fondo negro, sino abstractas como líneas paralelas, rojas y blancas, líneas aserradas, ganchos, elipses, etc.

Con respecto a la mínima aparición de fragmentos del estilo cerámico Campana en nuestra muestra, como todos sabemos, la cerámica es un objeto que se puede transportar fácilmente a grandes distancias. Pensamos que, debido a la alta movilidad de este elemento, se debería la presencia de solamente cuatro fragmentos de este estilo dentro de nuestra muestra, tanto en Cerro del Gentil como en Pampa del Gentil. Adicionalmente, no existe ningún elemento arquitectónico y estratigráfico que apoye la existencia de una ocupación particular en este sector relacionada con este estilo (Pérez, 2012; Velarde, 2006). Otro escenario plausible es que, como se ha registrado en otros sitios de Ica y Chincha (Massey, 1986 en 
Peters, 1997: 253; Velarde, 2006: 180), la cerámica de estilo Campana convivió por algún tiempo con el estilo Carmen y esto podría haber ocurrido en ambos sitios del valle medio de Chincha. Finalmente, también podría ser que, como parte de la construcción de sus edificaciones, los grupos sociales que utilizaron la cerámica Carmen hayan introducido fragmentos cerámicos de contextos más tempranos, no reconocidos aún por nosotros como una ocupación humana y eso explicaría la aparición de cerámica más temprana como Campana. La reutilización de elementos arquitectónicos y las intrusiones en las construcciones realizadas durante el periodo de uso de la cerámica de estilo Carmen pueden haber facilitado el disturbio de los posibles contextos vinculados al estilo cerámico Campana.

El establecimiento de las características morfofuncionales y decorativas permite reforzar la idea que el fenómeno Carmen funciona solamente a nivel de algunos valles, específicamente los de Chincha y Pisco (Silverman \& Proulx, 2002: 84). Por ello, se debe entender a Cerro del Gentil y Pampa del Gentil como parte del proceso social identificado con una tradición cerámica bastante característica y relativamente estandarizada en su producción, sobre todo la que presenta decoración pintada. A este nivel, podemos hablar de una producción especializada, aunque realizada en espacios domésticos que faltan descubrir. Asimismo, la presencia de la cerámica doméstica llana a escala significativa, con huellas de hollín, nos demuestra que la producción cerámica estaba sobre todo orientada hacia la preparación y consumo de alimentos. Estas actividades de distribución y consumo, además de la cerámica, se basan en el registro de una gran cantidad de restos de carbón, botánicos, de camélidos, malacológicos, etc.

Para Velarde (1993), la producción de la cerámica reflejaría la presencia efectiva de una sociedad de artesanos ceramistas «especialistas», capaces de producir la cerámica Carmen en talleres con técnicas de fabricación apropiadas y, obviamente, capaces de construir y mantener su arquitectura. De esta manera, Velarde apuesta por reconocer el estilo Carmen como una expresión particular de cerámica vinculada a una arquitectura vernacular en el valle de Chincha, que claramente se diferenció de otras regiones, especialmente de Nasca y probablemente con su extensión hasta el valle de Cañete y Pisco como señaló, en su momento, Wallace. Nuestras investigaciones sustentan dicha propuesta al ofrecer indicadores cuantitativos y cualitativos con relación a la cerámica de estilo Carmen en ambos sitios estudiados.

Obviamente, se necesita mucho más trabajo para comprobar las hipótesis referidas por otros autores y las que se han lanzado en este texto. Pero, quizá, lo más importante de este artículo sea la aportación de nuevos datos con el objetivo de generar una discusión actualizada de este estilo cerámico poco comprendido en la literatura de la arqueológica andina, a pesar de que, como hemos visto, ha estado presente desde hace ya más de 50 años e, incluso, se ha vinculado con una de las sociedades más famosas de la arqueología andina: la Nasca. Adicionalmente, este estudio concreto nos permite reconocer la forma en que las sociedades posparacas reocuparon y reorganizaron los espacios precedentes para poder seguir habitando, en comunidad, en una zona arqueológica que en los próximos años revelará una información valiosa para entender los procesos prehistóricos en la costa sur del Perú. 


\section{Agradecimientos}

Los autores desean agradecer a las diferentes instituciones y personas que hicieron posible la realización de las temporadas 2012 y 2013 del «Programa Arqueológico Chincha» (PACH). El Ministerio de Cultura del Perú facilitó los permisos para la ejecución de nuestras investigaciones arqueológicas. Asimismo, las becas ofrecidas por el Cotsen Institute of Archaeology de UCLA, la National Geographic Society y el Institute for Field Research posibilitaron los trabajos de campo y laboratorio. En la Dirección Regional de Cultura de Ica, Rubén García y Susana Arce nos brindaron todas las facilidades para el desarrollo de nuestro trabajo. En especial, queremos agradecer al Sr. Lucca Baraka propietario de la Empresa Agroexportadora Virgen del Rosario-Bamar y a sus administradores el Sr. Francisco Cánepa y el Sr. Luis García, por todas las facilidades de seguridad y apoyo logístico que nos han brindado en estos años. También, agradecemos a José Tumbalobos por su ayuda en la elaboración de ilustraciones que acompañan a este texto. Un agradecimiento final va para Julissa Ugarte a quien debemos el resumen en francés.

\section{Referencias citadas}

BACHIR, A. \& LLANOS, O., 2006 - El Gran Templo del Centro Ceremonial de Cahuachi (Nazca, Perú). Dimensión Antropológica, 38: 49-86.

CANZIANI, J., 1992 - Arquitectura y Urbanismo del Período Paracas en el Valle de Chincha. Gaceta Arqueológica Andina, 6: 87-117.

CANZIANI, J., 2009 - Ciudad y Territorio en los Andes: Contribuciones a la Historia del Urbanismo Prehispánico, 549 pp.; Lima: Fondo Editorial Pontificia Universidad Católica del Perú.

CASTRO-MARTÍNEZ, P., DE LA TORRE, J. C., ESCORIZA-MATEU, T., GODOY, M. C., LAPI, B., NAVARRO, I. \& ZAVALA, J. C., 2009 - Trabajo, Producción y Cerámica. Sociología de la Alfarería Paracas: Ocucaje y Tajo (Costa Sur de Perú). Estudios Atacameños, 37: 139-155.

KROEBER, A. \& STRONG, W. D., 1924 - The Uhle Pottery Collection from Ica. Publications in American Archaeology and Ethnology, 21(3): 95-134; University of California.

LANNING, E., 1960 - Chronological and Cultural Relationships of Early Pottery Styles in Ancient Peru; Berkeley: Departamento de Antropología, Universidad de California. Tesis doctoral.

LUMBRERAS, L.G., 2001 - Uhle y los Asentamientos de Chincha en el Siglo XVI. Revista del Museo Nacional, 49: 13-87.

LUMBRERAS, L. G., 2008 - La Présence de Paracas a Chincha. In: Catálogo de la Exposición «Paracas Trésors Inédits du Pérou Ancient »: 34-39; París: Musée du Quai Branly.

MENZEL, D., 1971 - Estudios Arqueológicos en los Valles de Ica, Pisco, Chincha y Cañete. Arqueología y Sociedad, 6: 1-100.

MENZEL, D., ROWE, J. \& DAWSON, L., 1964 - The Paracas Pottery of Ica: A Study in Style and Time, xiv + 399 pp.; Berkeley: University of California Press. American Archaeology and Ethnology 50.

MIDDENDORF, E., 1973 [1894) - Perú: Observaciones y Estudios del País y sus Habitantes Durante una Permanencia de 25 años; Lima: Universidad Nacional Mayor de San Marcos.

PÉREZ, K., 2012 - Caracterización Funcional del Sector B de Cerro del Gentil, Valle de Chincha a través de su Cerámica; Trujillo: Departamento de Arqueología. Universidad Nacional de Trujillo. Informe de Prácticas Pre-Profesionales. 
PETERS, A., 1997 - Paracas, Topará and Early Nasca: Ethnicty and Society on the South Central Andean Coast. Ithaca: Cornell University. Tesis doctoral.

PROULX, D., 1968 - Local Differences and Time Differences in Nasca Pottery, xi + 180 pp.; Berkeley: University of California Press. University of California Publications in Anthropology, Vol. 5.

PROULX, D., 2006 - A Sourcebook of Nasca Ceramic Iconography. Reading a Culture Throught Its Art, 274 pp.; lowa City: University of lowa Press.

PROULX, D., 2008 - Paracas and Nasca: Regional Cultures on the South Coast of Peru. In: Handbook of South American Archaeology (H. Silverman \& Isbell, W. eds.): 563585; New York: Springer.

SILVA, J. \& GARCIA, R., 1997 - Huachipa-Jicamarca: Cronología y desarrollo sociopolítico en el Rímac. Bulletin de l'Institut Français d'Études Andines, 26 (2): 195-228.

SILVERMAN, H., 1997 - The First Field Season of Excavations at the Alto del Molino Site, Pisco Valley, Peru. Journal of Field Archaeology, 24 (4): 441-457.

SILVERMAN, H., 2002 - Ancient Nasca Settlement and Society; lowa City: University of lowa Press.

SILVERMAN, H. \& PROULX, D., 2002 - The Nasca, xix + 339 pp.; Malden: Blackwell.

STRONG, W. D., 1957 - Paracas, Nazca and Tiahuanacoid Cultural Relationships in South Coastal Peru. Memoirs of the Society for American Archaeology, 13: 1-48.

TELLO, J. \& MEJÍA XESSPE, T., 2005 [1959] - Paracas. Primera parte, 534 pp.; Lima: T. Scheuch, S. A. Empresa Gráfica.

UHLE, M., 1924 - Explorations at Chincha. University of California Publications in American Archaeology, 21 (2): 55-94; Berkeley, California: University of California Press.

UNKEL, I., REINDEL, M., GORBAHNC, H., ISLA, J., KROMER, B. \& SOSSNA, V., 2012 - A Comprehensive Numerical Chronology for the Pre-Columbian Cultures of the Palpa valleys, South Coast of Peru. Journal of Archaeological Science, 39: 2294-2303.

VAUGHN, K., 2004 - Households, Crafts, and Feasting in the Ancient Andes: The Village Context of Early Nasca Craft Consumption. Latin American Antiquity, 15 (1): 61-88.

VAUGHN, K. \& LINARES, M., 2006 - 3,000 Years of Occupation in Upper Valley Nasca: Excavations at Upanca. Latin American Antiquity, 17 (4): 595-612.

VELARDE, L., 1993 - La Période des Développements Régionaux dans la Vallée de Chincha (Pérou) : La Phase "Carmen", 125 pp.; París: Université de Paris I, PanthéonSorbone, U.F.R. d'Historie de l'Art et d'Archéologie.

VELARDE, L., 1998 - La Fase "Carmen" en el valle de Chincha: Expresiones de una Sociedad Compleja en la Costa Sur del Perú. In: Union Internationale des Sciences Préhistoriques et Protohistoriques (UISPP): 421-427. A.B.A.C.O. Edizioni. Forlí. Actes du XIII Congrés, Tome V.

VELARDE, L., 1999 - La Transición Paracas-Nazca en el Valle de Chincha. In: L'Amérique du Sud : Des Chasseurs-Cueilleurs à L'Empire Inca (A. Chevalier, L. Velarde \& I. Chenal-Velarde, eds.): 63-77; Oxford: Oxbow Books. BAR International Series 746. Actes des Journées d'Archéologie Précolombienne, Genève, 10-11 octubre, 1997.

VELARDE, L., 2006 - El Intermedio Temprano en el Valle de Chincha (Perú): El Sitio de Pampa del Gentil. In: Préhistorire de l'Amérique. Change in the Andes: Origins of Social Complexity Pastoralism and Agriculture (Secretariado del Congreso, ed.): 171-181; Oxford: BAR International Series 1524. Actes du XIVème Congrès UISPP, Université de Liège, Belgique, 2- 8 septembre 2001. Section 17.

WALLACE, D., 1959 - Informe del Reconocimiento del Valle de Chincha. Revista del Museo Regional de Ica, 11: 31-40. 
WALLACE, D., 1971 - Sitios Arqueológicos del Perú (Segunda Entrega): Valles de Chincha y de Pisco. Arqueológicas, 13: 1-131.

WALLACE, D., 1986 - The Topará Tradition: an Overview. In: Perspectives on Andean Prehistory and Protohistory (D. Sandweiss \& P. Kvietok, eds.): 35-47; Ithaca: Cornell University. Latin American Studies Program.

ZIÓŁKOWSKI, S., PAZDUR, F., KRZANOWSKI, A. \& MICHCZYNSKI., A., 1994 - Andes Radiocarbon Database for Bolivia, Ecuador and Peru; Varsovia-Gliwice: Andean Archaeological Mission of the Institute of Archaeology/Warsaw University \& Gliwice Radiocarbon Laboratory of the Institute of Physics, Silesian Technical University. 